\title{
The Similarities and Differences of English Writing and Translation
}

\author{
WANG Shuang, JI Yan-hui \\ Changchun University, Changchun, China
}

\begin{abstract}
A close examination of the process and product of translation will let us realize that the key to determine a good or a bad translation hinges upon correct understanding and adept expression. Translation is possible to everyone, but with a difference of quality. The author believes that while realizing the multi-functions of translation studies, especially its function of cognition, we should not forget its essential function, i.e., the function of guiding translation practice. For a long time, people have confused the two concepts of "writing" and "translate”. To this, this paper analyzes the similarities and differences in English writing and translation.
\end{abstract}

Keywords: English writing, translation, similarities

\section{Introduction}

The similarities and differences between writing and translation are very hard to say. We are foreign language learners. English is our second language. So I think writing or translation is the way to learn English. Of course, there is no doubt that they are the different types in learning and using English. This paper introduces the definition of writing and creation at first, and then makes a comparison of "rewrite" and "translation". At last, the author finds out the differences and similarities between writing and translation.

\section{The Definition of Writing and Creation}

Mentioned in the "normal Chinese big dictionary", writing is commonly known as writing an article, it is an activity human using language and words or other symbols to process, record, and communicate the objective things, ideas, and information. "Modern writing" once pointed out that the so-called writing was that people used the language symbol to make the article a mental labor. While the "contemporary university writing" writes clearly that writing is a senior mental labor, and is also the activity writing subject expressing thoughts, feelings, and opinions with the organized words, and reflecting the objective world. The above three definitions of "writing" almost all mentioned "the use of language", which is the keyword of "writing".

$\mathrm{Ci}$ Hai thinks that creation refers to the creation of literary works. It is a complex mental labor with significant personality traits, and it should be greatly exerting the creativity of creation subject, including keen sensibility, deep insight, rich imagination, full recapitulation, and corresponding artistic expression skills.

WANG Shuang, lecturer, master, Public Foreign Languages Teaching and Research Department, Changchun University. JI Yan-hui, lecturer, master, Public Foreign Languages Teaching and Research Department, Changchun University. 
"Creative learning tutorial" thinks that creation is the intellectual activity directly producing the literary, artistic, and scientific works. Creation is to be created, be new, and be beyond our predecessors, myself, and age. At the same time, it does not deviate from the traditional root, but add new luster to art. Besides, creation is not deliberate innovation or difference.

Creation is the artistical expression of thinking. Other famous works also think that creation refers to the works of art and literature creation; it is a kind of spiritual labor. At the same time, it refers to the author observing, experiencing, researching, and analyzing the social life standing in a certain position with a certain world view as the instruction, and they also use a certain creation method and thinking method. The above three definitions of "creation" all almost uniformly referred to "create of art and literature works", which shows that “creative” prefers to arts.

\section{The Comparison of "Rewrite" and "Translation"}

\section{The Difference on the Nature of the Theory}

Lefevere regards "literary translation" as "rewrite" and also thinks that translation is the manipulation of original text for translator. And at the same time, the translator will be influenced and restricted by the sponsors, ideology, and poetics, etc. The evolution of literature is in the translator's text "rewrite" again and again. "Rewrite" is the meaning of "manipulation"; it can consolidate the existing ideology and poetics and also disassemble the both. "Rewrite" includes translation, history writing, collection, review, and compilation, etc. Translation is a creation form of another text image to a certain (or some) specific purpose, and the equivalent of the original is not possible. He thinks that the core of literary study is to explain and reveal the power in the literature, ideology, organization, and control. Rewriting is one of the key elements, and also the driving power of literary evolution. As such, rewrite goes far beyond the scope of traditional translation. Translation is only a form of rewriting.

\section{The Difference on Theory Foundation}

The "cultural turn" initiated by Bussnate and Lefevere (2001) breaks away from the traditional translation model limited to simple language transformation, and they broaden the field of vision of translation study by putting the study focus on the interaction between translation and culture. However, they go to the other extreme: They "overturn" the previous translation theories, particularly emphasize on the status of culture in translation, and also think the basic unit of translation is not word, sentence, or discourse, but culture. However, language is a part of almost every culture, and constantly passing on culture and language. Why if we left the language reflect culture? How to translate taking culture as the unit for us?

In Lefevere's view, different translation texts tell people that translation is the result of a lot of cultural interaction and text control. "Faithfulness" and "equivalence" are negative in the traditional level of language, and "control” is the inevitable phenomenon of translation. Lefevere thinks: "Faithful” is merely one of a variety of translation strategies, is also a kind of combining product of ideologies and poetics. Putting it as the only one possible, or even the only admissible strategy, is unrealistic and in vain.

\section{The Difference on Tasks}

The literature study theory of Lefevere takes translation as the object of literary study, and takes all translation behaviours as the result of the fait accompli to accept. Visibly, the theory of rewriting emphasizes on 
the objective description too much, lack of right and wrong value judgment of different form of rewriting. They do not focus on translation activity itself; it would be impossible to summarize the objective law of translation practice and guide translation practice.

\section{Differences of Writing and Translation}

\section{Writing Is Independent, Translation Will Depend on}

Although the author is constrained by writing rules, but, in contrast, he has absolute autonomy in the expression of ideas. Standing in front of him is a blank sheet of paper; he can decide his own work, such as subject, writing form, and structure. For translation, all seems to be all ready, including the content and structure of the article; the ideal state is to "copy" in another language. The translator can only say what the author puts it. Deviation from the original is destined to be considered a betrayal of the original author, deceiving new readers. Translation is doomed to have to rely on the original. This seems to only play in sample picture of the ladle translation writing ability to draw. For writing, people generally do not compare it with other articles, much less in form and what set up on the language standard. Of course, if it is a piece of literature, it may be influenced by the literary theories and thoughts of judge. Writing is inductive your thoughts. Nobody will say what an essay writing betrays, but only what it preaches.

\section{More Direct Experience in Writing, While Indirect Experience in Translation}

In general, writing is regarded as the record of the author's life, experience, and observation, so the author needs field trips. Many literary works, such as "beautiful snow" and "red rock", the author all involved, and even risked their lives to get experience. Of course, part of the author is feeling comes from indirect experience, through reading literature. And translation is that the translator will content vector from one language into another language vector. The author's direct experience becomes indirect experience of the translator; the translator processing work has been the author of their experience after processing the finished product. The translator can only write from the author's narration middle ground perception based on direct experience. As a result, some translators will use to visit abroad, to participate in conferences such as the opportunity, not far from thousands of miles to visit, the feelings of the author lived, fought, the purpose is to more vividly image the direct experience of the author, as a "tour" of the writer.

\section{Difference on Reader Objects}

Pure writing readers that are the authors are fundamentally different with the readers suffered with the barriers of language and culture. The author and the reader have a common social, cultural, and religious background; they can not only talk, but also sense the beauty of the original. The author's heart is interlinked with the heart of readers. And the social, cultural, and religious background of original author is not directly associated with the translation readers; there is an insulation layer between the reader and the translator. Naturally, the information will be reduced or unclear. So it is difficult to experience the reader's expression in the deeper level of information for the author, including language; all have to wait for the translator to spit again after chewing feed from the original.

\section{Similarities of Writing and Translation}

Both writing and translation must be based on a lot of reading. Through the ages, many writers discussed the 
function of reading for writing. The Tang dynasty poet Du Fu's poem "Read Rolls, Such as Writing”, in spite of the familiarity, we still have to refer to it. Reading is imperceptible to the promoting effect of writing; it tends to have a gradual process from the accumulation of reading to writing. Higher request for reading than writing, translation, different lies in the writing of reading can be any time before, and even many years ago, the content of the reading may and writing content. Reading and translation can be three types: The first is similar to reading before writing, namely seasky and extensive reading; the second is closely related to the reading of translation subjects; the third is the translated text reading. Only by reading the original text deeply can the translator accurately write idiomatic translation and make suitable combination of the original words, phrases, sentences, paragraphs, chapters, prose style, and so on.

\section{The Essential Requirement for Practice}

Both writing and translation are color words which have strong practice activities, not just talking. Perusal writing theory cannot write successful works; only reading translation theory book does not produce good products. The basis of practice is into the life, rather than “young doesn't know the taste of sorrow, but strongly say sorrow to assign a new works” (Snyder, 2000, pp. 137-139). The author can try to write down the things of more deep feelings, narrative, description, and lyrical every day, and discuss them for the writing of articles. Over time, people will form the good habit of writing, and will unconsciously improve writing level, so does the translation. No matter how high the theoretical level is and how wonderful the mastering skill is, people must do not know where to start without a lot of translation practice.

\section{Brushwork of Writing and Translation}

In Chinese traditional culture, calligraphy, painting, writing, etc., all pay more attention to the "brushwork". One of the most famous is "chunqiubifa". "The brushwork of translation" is an important concept of translation in the studies of Wang Hongy. In theory, translation brushwork comes from writing; it is a long-term process of accumulation. Translation is basic brushwork writing skill; it has a set of personal idiomatic vocabularies and writing styles. Some writers and translators are used to use their own ways to translate; most translators are in habit of writing himself into translation. Brushwork is the skill and handling concluded by translator after long rich translation practice. Although translation brushwork and writing has the homologous relationship, conscious translator should try to avoid the personal writing habits into translation in writing.

\section{Conclusion}

At this stage of learning and reading, people always confuse the two concepts of writing and translation, which seriously influence people's judgment, understanding, and the future development. In this article, we carry on the contrast of the "rewrite" and "translation writing" and draw the similarities and differences between the two. At the same time, understanding the similarities and differences between the two is conducive to learning in the future.

\section{References}

Bassnet, S., \& Lefevere, A. (2001). Constructing cultures: Essays on literary translation. Shanghai: Shanghai Foreign Language Education Press.

Bell, R. T. (2001). Translation and translating: Theory and practice. Beijing: Foreign Language Teaching and Research Press. 
Graddol, D. (2001). English in the future. In A. Burns \& C. Coffin. (Eds.), Analysing English in a global context (pp. 123-126). London: Routledge.

Lefevere, A. (2004). Translation, rewriting, and manipulation of literary fame. Shanghai: Shanghai Foreign Language Education Press.

Robinson, D. (2001). Who Translates?-Translator subjectivities beyond reason. New York: State University of New York Press. Shttleworth, M., \& Cowie, M. (2004). Dictionary of translation studies. Shanghai Foreign Language Education Press.

Catford, J. C. (1965). A linguistic theory of translation: An essay on applied linguistics. London: Oxford University Press.

Snyder, G. (2000). Reflections on my translation of the T'ang poet Han-shan (pp. 137-139). Manoa: University of Hawai Press. 